GRIPS Discussion Paper 13-12

\title{
Robust Determinants of Growth in Asian Developing Economies: A Bayesian Panel Data Model Averaging Approach
}

\author{
Roberto Leon-Gonzalez \\ Thanabalasingam Vinayagathasan
}

July 2013

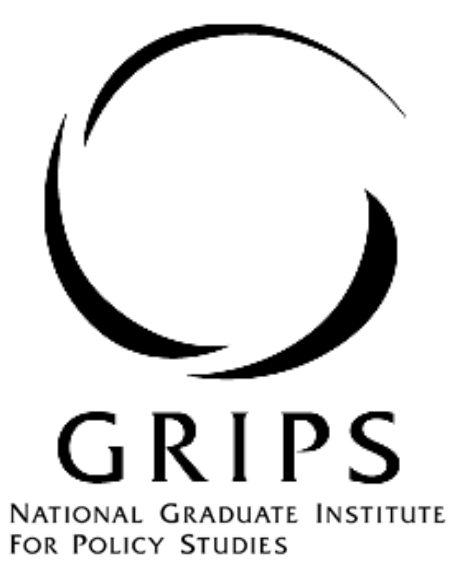

National Graduate Institute for Policy Studies 7-22-1 Roppongi, Minato-ku,

Tokyo, Japan 106-8677 


\title{
Robust Determinants of Growth in Asian Developing Economies: A Bayesian Panel Data Model Averaging Approach
}

\author{
Roberto Leon-Gonzalez* \\ and \\ Thanabalasingam Vinayagathasan $^{* *}$
}

July 2013

\begin{abstract}
This paper investigates the determinants of growth in the Asian developing economies. We use Bayesian model averaging (BMA) in the context of a dynamic panel data growth regression to overcome the uncertainty over the choice of control variables. In addition, we use a Bayesian algorithm to analyze a large number of competing models. Among the explanatory variables, we include a non-linear function of inflation that allows for threshold effects. We use an unbalanced panel data set of 27 Asian developing countries over the period 1980-2009. Our empirical evidence on the determinants of growth suggests that an economy's investment ratio and trade openness are positively correlated to growth, whereas government consumption expenditure is negatively correlated. Further, our empirical results indicate a substantial probability that inflation impedes economic growth when it exceeds $5.43 \%$. We also find no evidence of conditional convergence or divergence.
\end{abstract}

Keywords: Determinants of Growth, Bayesian Model Averaging, Panel Data Model, Inflation Threshold

JEL Classification: O40, E31, C11, C23

\footnotetext{
* National Graduate Institute for Policy Studies (GRIPS). 7-22-1, Roppongi, Minato-ku, Tokyo 106 8677, Japan E mail: rlg@grips.ac.jp

** Corresponding author. National Graduate Institute for Policy Studies (GRIPS). 7-22-1, Roppongi, Minato-ku, Tokyo 106 8677, Japan. E mail: vinayagamkili@yahoo.com
} 


\section{$1 \quad$ Introduction}

Some countries grow faster than others. Why does this happen? Many empirical studies have focused on this issue by regressing the observed GDP per capita growth rate on a number of explanatory variables (e.g., Kormendi and Meguire, 1985; Grier and Tullock, 1989; Romer, 1990; Barro, 1991; Aghion and Howitt, 1992; Sala-i-Martin, 1997a, b; Hall and Jones, 1999; Durlauf and Quah, 1999; Temple, 1999; Fernandez et al., 2001a, b; Sala-i-Martin et al., 2004). However, the number of potential regressors suggested by competing growth theories is large, with the potential problem of over-parameterization (see, for example, Koop and Tole, 2004b). For this reason it is not recommended to include all the potential regressors in a model.

On theoretical grounds, researchers have not reached a consensus on the set of explanatory variables that have an effect on growth. Furthermore, there is a myriad of possibilities in the empirical literature. For example, Sala-i-Martin (1997a, b) considers 59 potential regressors, whereas Fernandez et al. (2001a) consider 41 and Sala-i-Martin et al. (2004) had 67 potential regressors.

Previous empirical growth studies have proposed different econometric techniques to address the issue of model uncertainty, that is, the uncertainty regarding which factors explain the growth differences across countries. Typically, researchers have to deal with a large number of empirical growth models, each one consisting of a different combination of explanatory variables. Each of these models has some probability of being the "true" model. Bayesian model averaging (BMA) is a widely accepted technique to overcome the problems associated with the selection of a single model, and has been used in many recent empirical growth studies. This method was popularized in the growth literature by the seminal works of Fernandez et al. (2001a, FLS henceforth) and Sala-i-Martin et al. (2004, SDM henceforth). Since then, it has been applied in several growth empirical studies (e.g., Ciccone and Jarocinski, 2010; Moral-Benito, 2010, 2012; Koop et al., 2012; León-González and Montolio, 2012) and other areas of economics (e.g., Koop and Tole, 2004a; Chen et al., 2011).

Most previous empirical studies using BMA dealt only with the model uncertainty that results from different choices of control variables. However, as noted by Caselli et al. (1996), the failure to account for country-specific fixed effects and the endogeneity of regressors might 
render cross-country growth regression estimates inconsistent. These problems might arise from measurement errors, omitted variable bias, and simultaneous effects. However, the econometric techniques to solve these problems need to rely on a choice of instruments and exogeneity restrictions. This adds another layer of difficulty to the model selection problem. To take this into account, Koop et al. (2012; henceforth KLS) and León-González and Montolio (2012; henceforth LM) extended the BMA approach to consider the additional dimensions of model space.

Many of the empirical growth models mentioned above take into account model uncertainty on the assumption of a linear relationship between growth and its determinants. However, evidence shows that some of the growth determinants might have an effect on growth non-linearly. For instance, inflation (e.g., Fischer, 1993; Khan and Senhadji, 2001; Bick, 2010; Yilmazkuday, 2011), government size, the number of years the economy has been open, and initial income per capita (e.g., Crespo-Cuaresma and Doppelhofer, 2007; Yilmazkuday, 2011) might have a non-linear effect on growth.

Therefore, in this study, we consider a non-linear function that allows for a threshold in the impact of inflation on growth. By following the BMA methodology in KLS and LM, we take into account model uncertainty over the set of controlling regressors in a dynamic panel data growth regression. Since we have a large model space in our empirical application, we compute by using the reversible-jump Markov Chain Monte Carlo (RJMCMC) algorithm suggested by KLS.

In this paper, we use an unbalanced panel data set covering 27 Asian developing countries over the period 1980-2009 and consider 14 explanatory variables. In order to eliminate business cycle fluctuations, we take two-year averages, and thus, the actual number of time observations is halved. Since we include fixed effects in the estimation, we do not include time-invariant regressors. Therefore, the number of explanatory variables we use is smaller than that used in other BMA applications in a cross-section context.

The rest of the paper is organized as follows. Section 2 briefly discusses the econometric framework of this study. The data and details of the variables are described in Section 3. Section 4 presents the estimation results of the econometric model and its findings. In Section 5, we 
compare our results with those from other estimation methods. Finally, in Section 6, we conclude the paper.

\section{Econometric Framework}

In our basic model setup, we use a simultaneous equations model (SEM) with dynamics in a panel data framework. This allows us to control for individual fixed effects and simultaneity. First, we define the main structural equation as follows:

$$
g_{i t}=\gamma^{\prime} h_{i t}+\beta^{\prime} x_{i t}+\mu_{i}+u_{i t}
$$

where $i$ denotes the cross-sectional dimension (for $i=1, \ldots, \mathrm{N}$ ), $t$ is the time dimension (for $\mathrm{t}=1, \ldots, \mathrm{T}), \mathrm{g}_{\mathrm{it}}$ is the gross domestic product (GDP) per capita growth rate for country $i$ at time $t, h_{i t}$ denotes an $\mathrm{M} \times 1$ vector of endogenous regressors ${ }^{1}$ for country $i$ at time $t, x_{i t}$ represents a $\mathrm{k}_{1 \mathrm{j}} \times 1$ vector of exogenous explanatory variables for country $i$ at time $t$ (see Table 1 for a description of the variables), $\mu_{i}$ indicates the unobserved individual heterogeneity, and $u_{i t}$ is the error term with zero mean and no serial correlation. The sub-index $j$ in $\mathrm{k}_{1 \mathrm{j}}$ denotes the model, and it implies that the number of exogenous regressors in each model could be different. Regarding the dimension of $h_{i t}$, we fix it as $M$ for all models, but allow gamma to have zero elements. Thus, in practice, we can have a different number of endogenous regressors in each model.

\subsection{Fixed-Effect Elimination}

In the first phase of the estimation method, we need to eliminate the unobserved country-specific fixed effects. For that purpose, we should apply forward orthogonal deviation (FOD) transformation to the dynamic equation (1). This transformation is preferred to first-differencing transformation because it does not introduce serial correlation in the error term. FOD transformation subtracts the average of all future available observations. Therefore, the formula for transforming a variable, $u_{i t}$, is given by

\footnotetext{
${ }^{1}$ In our empirical application, we have only one endogenous variable, the initial level of GDP per capita. Thus, $h_{i t}$ is $1 \times 1$.
} 


$$
u_{i t}^{*}=\sqrt{\frac{T-t}{T-t+1}}\left[u_{i t}-\frac{1}{(T-t)}\left(u_{i(t+1)}+\cdots+u_{i T}\right)\right]
$$

By applying this procedure to equation (1), we obtain

$$
\mathrm{g}_{\mathrm{it}}^{*}=\gamma^{\prime} \mathrm{h}_{\mathrm{it}}^{*}+\beta^{\prime} \mathrm{x}_{\mathrm{it}}^{*}+\mathrm{u}_{\mathrm{it}}^{*}
$$

where $t=1, \ldots, \mathrm{T}-1$ (therefore, we lose one observation). This transformation ensures that if $\operatorname{Var}\left(u_{i t}\right)=\sigma^{2} I_{T}$ with no serial correlation, then we also have $\operatorname{Var}\left(u_{i t}^{*}\right)=\sigma^{2} I_{T-1}$ with no serial correlation. Moreover, as noted by LM, this transformation can also be explained from a Bayesian perspective. The transformation comes from integrating out the fixed individual effects from the posterior density by using a flat prior.

\subsection{Solving the Endogeneity Problem}

Equation (3) cannot be estimated with ordinary least squares (OLS) estimation because there is a correlation between $h_{i t}^{*}$ and $u_{i t}^{*}$. In our empirical application, $h_{i t}$ contains only the initial GDP per capita level. Even if we assume that $h_{i t}$ is uncorrelated with $u_{i t}$, it is clear that the transformation induces a correlation between $h_{i t}^{*}$ and $u_{i t}^{*}$. To solve this problem, we use instrumental variables. In particular, we use the Bayesian analogue of the two-stages-leastsquares (2SLS) estimator as suggested by LM (2012). Then, the system of equations containing auxiliary equations for $h_{i t}^{*}$ can be defined as follows:

$$
\begin{aligned}
& g_{i t}^{*}=\gamma^{\prime} h_{i t}^{*}+\beta^{\prime} x_{i t}^{*}+u_{i t}^{*} \\
& h_{i t}^{*}=\Pi_{x} x_{i t}^{*}+\Pi_{z} z_{i t}+v_{i t}^{*}
\end{aligned}
$$

where $\mathrm{z}_{\mathrm{it}}$ is a $k_{2 j} \times 1$ vector of predetermined instruments and the error terms $u_{i t}^{*}$ and $v_{i t}^{*}$ are normally distributed with zero mean and mutually uncorrelated across the cross sections and over time. That is, $\mathrm{E}\left(\mathrm{u}_{\mathrm{it}}^{*}, \mathrm{v}_{\mathrm{js}}^{*}\right)=0$ for either $i \neq \mathrm{j}$ or $t \neq \mathrm{s}$ or both. We assume that the variables $x_{i}$ and $z_{i}$ are exogenous; thus,

$$
E\left(x_{i t}^{*},\left[\begin{array}{c}
u_{i t}^{*} \\
v_{i t}^{*}
\end{array}\right]^{\prime}\right)=0 \text { and } E\left(z_{i t},\left[\begin{array}{c}
u_{i t}^{*} \\
v_{i t}^{*}
\end{array}\right]^{\prime}\right)=0
$$

The predetermined instruments are typically constructed using lags of $h_{i t}$. Hence, as an instrument for the transformed initial GDP per capita level, $h_{i t}^{*}$, we use the untransformed value 
$\left(h_{i t}\right)$. Although we can use further lags as instruments, no clear guidelines exist on the optimal number of instruments. Using Monte Carlo simulation, Roodman (2009) proposed that increases in the instrument count tend to raise the estimate of a parameter. Windmeijer (2005) reports that reducing the instrument count by a certain amount lowers the average bias of the interest parameter, whereas LM (2012) shows that models using nearer lags as instruments have larger posterior probability. For this reason, we use only one instrument in our estimation, $\mathrm{h}_{\mathrm{it}}$. The moment condition associated with this instrument is

$$
E\left(u_{i t}^{*}, h_{i, t}\right)=0 \text { for } t=1, \ldots \ldots, \mathrm{T}-1
$$

The dimensions of parameter matrices $\left(\Pi_{x}, \Pi_{z}, \beta\right)$ differ over model space. Following KLS, the model space in our empirical application includes all the just-identified and overidentified models verifying the restriction $\mathrm{k}_{2 \mathrm{j}} \geq \mathrm{M}$. Further, we assume that the coefficient matrix of the instruments $\left(\Pi_{z}\right)$ has full rank. Therefore, the model space consists of models that differ on the following aspects:

$\checkmark$ Variables in $x_{i t}: x_{i t}$ is a subset of a larger group of potential exogenous regressors denoted by $\mathrm{X}$, which are not allowed to be instruments. Therefore, there is uncertainty over the dimensions of $x_{i t}$ and $\beta$.

$\checkmark$ Set of instruments: Although this technique can consider models with a different set of instruments in principle, in our application, all the models use the same instrument, that is, $\mathrm{h}_{\mathrm{it}}$. Therefore, we do not consider uncertainty over the set of instruments.

$\checkmark$ Exogeneity restrictions: Although, in principle, some of the covariances between the error terms $\left(u_{i t}\right.$ and $\left.v_{i t}\right)$ can be restricted to zero, in our setup, we have only one endogenous variable (initial GDP per capita level), which we are certain must be treated as endogenous. Therefore, in our setup there is no uncertainty over exogeneity restrictions.

$\checkmark$ Restrictions on coefficients of endogenous or predetermined regressors: Some of the coefficients of $\gamma$ might be restricted to zero. In our case, $\gamma$ is a scalar parameter. In some models, it will be restricted to zero. A zero value of $\gamma$ implies that there is neither conditional convergence nor conditional divergence among countries. 
As shown in KLS, the model space consists of $2^{2 \mathrm{M}} \mathrm{N}^{\mathrm{A}}$ number of models, with $\mathrm{N}^{\mathrm{A}}$ taking the form

$$
\mathrm{N}^{\mathrm{A}}=\sum_{\mathrm{j}=\mathrm{M}}^{k_{2}^{T}} 2^{k_{1}^{T}+k_{2}^{T}-\mathrm{j}} \mathrm{C}_{\mathrm{j}}^{k_{2}^{T}}
$$

where $k_{1}^{T}$ denotes the total number of potential regressors in $\mathrm{X}, k_{2}^{T}$ the total number of potential instruments, and $\mathrm{C}_{\mathrm{j}}^{k_{2}^{T}}$ the combinatorial number. In our empirical analysis, we have only two endogenous regressors including the dependent variable $(M=2), 1$ instrument $\left(k_{2}^{T}=1\right)$ and 13 exogenous variables $\left(k_{1}^{T}=13\right)$. Thus, the number of models can be calculated ${ }^{2}$ as $2^{14}$.

\subsection{Bayesian Model Averaging Approach in Panel Data}

A basic strategy for model selection is to choose the most plausible model $H_{j}$, specifically, the one with the highest posterior model probability, $p\left(H_{j} \mid Y\right)$. Posterior model probability is defined as

$$
\mathrm{p}\left(\mathrm{H}_{\mathrm{j}} \mid \mathrm{Y}\right)=\frac{f\left(\mathrm{Y} \mid \mathrm{H}_{\mathrm{j}}\right) \mathrm{p}\left(\mathrm{H}_{\mathrm{j}}\right)}{\sum_{\mathrm{r}=1}^{\mathrm{K}} f\left(\mathrm{Y} \mid \mathrm{H}_{\mathrm{j}}\right) \mathrm{p}\left(\mathrm{H}_{\mathrm{j}}\right)}
$$

where $Y$ represents all the observed data, $f\left(Y \mid H_{j}\right)$ is the marginal likelihood of model $H_{j}$, and $p\left(H_{j}\right)$ is the prior probability that model $H_{j}$ is true; $\mathrm{K}=2^{2 \mathrm{M}} \mathrm{N}^{\mathrm{A}}\left(=2^{14}\right)$ is the total number of models such that the summation takes place over the whole model space. Thus, equation (8) implies that the posterior probability of model $H_{j}$ is proportional to the prior model probability times the marginal likelihood of the model. The marginal likelihood of model $H_{j}$ can be given by

$$
f\left(\mathrm{Y} \mid \mathrm{H}_{\mathrm{j}}\right)=\int f\left(\mathrm{Y} \mid \theta, \mathrm{H}_{\mathrm{j}}\right) \mathrm{p}(\theta) \mathrm{d} \theta
$$

where $\theta$ denotes the unknown parameters of model $H_{j}, p(\theta)$ is the prior for parameter $\theta$ under model $H_{j}$, and $f\left(Y \mid \theta, H_{j}\right)$ is the likelihood of that model.

\footnotetext{
${ }^{2}$ Note that although the direct application of the formula gives $2^{15}$ models, we have only $2^{14}$ models because we do not allow $h_{i t}^{*}$ to be treated as exogenous.
} 
However, selecting the model with the highest probability ignores the problem of model uncertainty since it disregards the models that also have some positive probability of being true. BMA solves this problem by calculating the weighted average over all the models such that the weights are proportional to the posterior probabilities of the models.

The inference for $\theta$ can be constructed on the basis of the posterior distribution

$$
f(\theta \mid \mathrm{Y})=\sum_{\mathrm{j}=1}^{\mathrm{K}} f\left(\theta \mid \mathrm{H}_{\mathrm{j}}, \mathrm{Y}\right) \mathrm{p}\left(\mathrm{H}_{\mathrm{j}} \mid \mathrm{Y}\right)
$$

Equation (10) shows that the full posterior distribution of $\theta$ is the weighted average of the posterior distribution under each model, where the weights are proportional to the posterior model probabilities, $p\left(H_{j} \mid Y\right)$. BMA allows for computing the probability of including a regressor, which is the probability that the regressor has a non-zero coefficient:

$$
p\left(x_{i t} \mid Y\right)=\sum_{j=1}^{K} I\left(x_{i t} \mid H_{j}\right) p\left(H_{j} \mid Y\right)
$$

where $x_{i t}$ is an explanatory variable and $I\left(x_{i t} \mid H_{j}\right)$ is an indicator function that takes the value 0 if the coefficient of $x_{i t}$ is restricted to zero under model $H_{j}$ and 1 otherwise. Furthermore, the posterior mean of $\theta$ can be calculated from the posterior distribution in equation (10) as

$$
E\left(\theta_{i} \mid Y\right)=\sum_{j=1}^{K} E\left(\theta_{i} \mid Y, H_{j}\right) p\left(H_{j} \mid Y\right)
$$

From expression (12), we see the posterior mean for $\theta$ as a weighted average of the posterior means under each model.

Implementation of the BMA procedure presents three challenges. First, we need to choose the prior model probabilities $p\left(H_{j}\right)$ and the prior for parameters $p\left(\theta \mid H_{j}\right)$. In our empirical study, we assume that all the models exhibit equal prior probabilities, implying that the prior over the model space is uniform: $p\left(H_{1}\right)=p\left(H_{2}\right)=\cdots=p\left(H_{\mathrm{K}}\right)=\frac{1}{\mathrm{~K}}$. With regard to choice of priors for parameters, we follow the same setup as in LM. Second, the marginal likelihood $f\left(H_{j} \mid Y\right)$ depends on an integral that cannot be solved analytically. This can be calculated only through a 
computationally intensive numerical approach. Finally, the model space in our empirical application contains approximately $2^{14}$ models, which is computationally challenging. To overcome these challenges, we apply the RJMCMC algorithm developed by KLS as a computational strategy. This algorithm iteratively obtains values for models $\left(H_{j}\right)$ and parameters

$(\theta)$. Given the arbitrarily fixed initial values for $\left(\theta, H_{j}\right)$, we can use the generated values as a sample from the posterior of $\left(\theta, H_{j}\right)$ after an adequate number of iterations. With this sample, we can compute the quantities of interest, such as the posterior probabilities of models and confidence intervals for parameters.

\section{$3 \quad$ Data and Variables}

Tables 1 and 2 in the appendix show the lists of variables used in our growth regression, with definitions, data sources, and some descriptive statistics. Our dataset spans the period 1980-2009 for 27 Asian developing countries (see Table 3 for the list of countries), and we extend the dataset used by Vinayagathasan (2013) by adding some more explanatory variables. Since the values for school enrollment in primary and secondary education are missing, our dataset is unbalanced. However, this does not affect the methodology that we use. To allow for the threshold effects of inflation, we build on Vinayagathasan (2013), who used a dynamic panel threshold growth regression approach (Kremer et al., 2009) and estimated the threshold level as $5.43 \%$. Accordingly, in the set of explanatory variables, we include the following two inflationrelated variables:

$$
\begin{aligned}
& \text { inf_low }=\text { inflation* } \mathrm{d}_{\mathrm{I}} \\
& \text { inf_high }=\text { inflation*d } \mathrm{d}_{\mathrm{I}}
\end{aligned}
$$

where $\mathrm{d}_{\mathrm{I}}$ is a binary indicator that takes the value of 1 when inflation is below the threshold and 0 otherwise. Therefore, the coefficient of inf_low gives the impact when inflation is below the threshold level and the coefficient of inf_high gives the impact when inflation is above the threshold level.

Several studies estimate the determinants of growth by taking the averages of four-year periods (e.g., LM, 2012; Chen et al., 2011), five-year periods (e.g., Bick, 2010; William and Wacziarg, 2004; Gylfason and Herbertsson, 2001), and ten-year periods (e.g., Moral-Benito, 
2010). However, in this paper, the number of countries is comparatively small because we focus only on Asian countries. Therefore, to maximize the number of observations, we use nonoverlapping two-year period averages.

\section{$4 \quad$ Estimation Results}

In order to carry out BMA analysis, we run the RJMCMC algorithm for 300000 iterations after discarding the initial 10000 values. To check the convergence of the algorithm, we calculate the "total visited probability"3 (TVP), as shown in George and McCulloch (1997) and LM (2012), and obtain a value close to 1 (0.999), which indicates good convergence. Furthermore, we run the model many more times with randomly drawn initial values and obtain almost the same results.

As shown in Table 4, the exogenous regressors with a posterior probability of inclusion close to 1 are investment ratio, trade openness, secondary school enrollment rate, and population. The estimated coefficient of the investment ratio is clearly positive, because a $95 \%$ credible interval does not include 0 and the posterior probability that the coefficient is positive is close to 1. Although the $95 \%$ credible intervals for trade openness and population ${ }^{4}$ do contain the value 0 , both of them have a substantial posterior probability of being positive $(65.4 \%$ and $73.8 \%$, respectively). However, the posterior probability that the coefficient of secondary education is positive is only $52.2 \%$, indicating that the sign cannot be clearly established (that is, the probability that the coefficient is positive is almost the same as the probability that it is negative). Government consumption expenditure has a high posterior probability of inclusion (85.1\%), and as Table 4 shows, the probability that government consumption has a negative impact on growth is also $85.1 \%$. Finally, the regressor "inflation above threshold level" (inf_high) has a probability of around 53.6\% of having a non-zero impact on growth; the probability of having a negative impact is approximately $53.3 \%$. This indicates a substantial probability that the impact of inflation on growth is negative whenever inflation is beyond the threshold value of 5.43\%. On the other hand, since the posterior inclusion probability of inflation below the threshold (inf_low)

\footnotetext{
${ }^{3}$ Total visited probability is an estimate of the fraction of the total posterior probability mass visited by the chain (for more details, see LM 2012).

${ }^{4}$ However, our sample includes China and India, and this might have an impact on the estimated coefficient. When we carry out BMA analysis without these two countries, the posterior inclusion probability of population becomes almost 0 , while the other results are very similar to our main findings (available upon request). Therefore, China and India seem to play a significant role in explaining the positive impact of population on growth.
} 
is almost 0 , we can conclude that any inflation below the threshold value has no impact on growth. These conclusions are consistent with Vinayagathasan (2013), who analyzed a similar dataset using GMM estimation.

The remaining regressors (growth rate of population, terms of trade, labor force participation rate, primary school enrollment rate, price level of investment goods, and population density) have very small probabilities of inclusion. Thus, they do not seem to explain the economic growth of the Asian developing countries. However, the impact of these variables might be country specific.

In sum, the investment ratio of an economy is positively associated with its growth rate whereas government consumption expenditure is negatively correlated. Evidence also indicates that trade openness stimulates economic growth. Further, substantial evidence shows that inflation hurts economic growth when it is beyond the threshold value of $5.43 \%$ but does not have any significant effect on growth below that level.

Recall that we have treated the "initial level of GDP per capita" as an endogenous regressor. As shown in Table 5, the posterior probability of including the initial level of GDP per capita is only $17.2 \%$, implying that the probability that its coefficient is 0 is as high as $82.8 \%$. This indicates that countries are conditionally neither converging nor diverging. That is, if the other growth determinants are constant, the initial value of GDP will not be important. To understand this, note that each country has a different resource endowment, but we control for this by including the fixed effects. This could be the reason why we find no conditional convergence or divergence. Although the neoclassical growth model (Solow model; Solow, 1956) proposes conditional convergence, LM (2012) finds that countries are conditionally neither converging nor diverging when using the whole sample with fixed effects.

\section{Comparison with Other Estimation Methods}

In the previous section, we considered initial income as a predetermined regressor and controlled for country fixed effects. For a comparative study, let us first carry out a more basic BMA analysis, assuming that all the regressors are exogenous in a pooled regression context, with no 
fixed effects ${ }^{5}$. The results obtained vary in three different aspects (see Table 6). First, the regressors population density and labor force participation rate, which showed a very small probability of inclusion, become significant and positively correlated to growth with a higher posterior inclusion probability (93.2\% and 67.2\%, respectively). Second, the probability of inclusion of regressors "trade openness" and "government consumption expenditure" decreased from nearly 1 to close to zero. Finally, inflation above the threshold level became insignificant, with a probability of inclusion close to zero. With respect to similarities, the investment ratio and population are positively correlated to growth, with a probability of inclusion close to 1 in both cases.

In addition to the basic BMA analysis, we carry out a comparative study by using estimation methods that allow for endogeneity and/or fixed effects but not model uncertainty, such as the Generalized Method of Moment (GMM: Arellano and Bond, 1991), Fixed Effect (FE: Wooldridge, 2010, chapter 10), and the bias-corrected Least Square Dummy Variable (LSDVC: Judson and Owen, 1999) estimators. The results show that one of the regressors that was earlier found significant with our main BMA analysis, secondary school enrollment rate, now became insignificant. Further, the effect of the threshold variable (inflation above the threshold level) on growth is significant and negative in all the three cases (see Table 7). Moreover, as in the main BMA analysis, the GMM estimator also finds that population and trade openness are vital factors to determine the growth rate, whereas the FE and LSDVC estimators do not find so. Fourth, government consumption expenditure is significant and negatively correlated to the growth rate according to the GMM and FE estimators but not according to the LSDVC estimator. Finally, the investment ratio, which was found significant with our main BMA approach, is also found significant with these three approaches.

While the standard BMA analysis did not take into account endogeneity or fixed effects, the three approaches, GMM, FE, and LSDVC, do not consider the issue of model uncertainty. However, our main BMA analysis considered the issues of model uncertainty, endogeneity, and fixed effects simultaneously.

\footnotetext{
${ }^{5}$ The analysis was carried out with the R software and the "BMA R package" of version 3.15.1.
} 


\section{Conclusions}

The existing empirical studies have used various techniques to account for model uncertainty in growth regressions. Among these techniques, BMA analysis was widely used and is presently the most prominent approach to overcome model uncertainty in the empirical growth literature. In this paper, we used a recent technique to carry out BMA analysis in the context of a dynamic panel data model with fixed effects. Only a few empirical growth studies have considered these issues in their model setup. Furthermore, our study is novel in that we allow for a threshold level such that inflation has an impact on economic growth and we focus on Asian countries.

Our empirical evidence on the determinants of growth has found three variables, namely, investment ratio, trade openness, and government consumption expenditure, to have a significant impact on growth. We also found that the countries are conditionally neither converging nor diverging because the probability of their coefficient of initial income being zero is as high as $82.8 \%$.

In addition, we found that any inflation above the threshold level of 5.43\% has a negative impact on growth with a 53\% probability. Although this probability is not as high as for the other determinants of growth, we consider its size to be sufficiently high to warn the policy makers in Asia about the potentially damaging effect of inflation on growth. However, one limitation of this study is that we did not distinguish between expected and unexpected inflation or look into the impact of inflation volatility. We leave this subject matter for future research.

\section{References}

Aghion, P. \& P. Howitt (1992) A model of growth through creative destruction. Econometrica 60, 323-351.

Arellano, M. \& S. Bond (1991) Some tests of specification for panel data: Monte Carlo evidence and an application to employment equations. Review of Economic Studies 58, 277-297.

Barro, R. J. (1991) Economic growth in a cross section of countries. Quarterly Journal of Economics 106, 407-444.

Bick, A. (2010) Threshold effects of inflation on economic growth in developing countries. Economics Letters 108(2), 126-129.

Caselli, F., G. Esquivel, \& F. Lefort (1996) Reopening the convergence debate: A new look at cross-country growth empirics. Journal of Economic Growth 1(3), 363-389. 
Chen, H., A. Mirestean, \& C. G. Tsangarides (2011) Limited information Bayesian model averaging for dynamic panels with an application to a trade gravity model. IMF working paper $\mathrm{WP} / 11 / 230$.

Ciccone, A. \& M. Jarocinski (2010) Determinants of economic growth: Will data tell? American Economic Journal: Macroeconomics 2, 222-246.

Crespo-Cuaresma, J. \& G. Doppelhofer (2007) Nonlinearities in cross-country growth regressions: A Bayesian averaging of thresholds (BAT) approach. Journal of Macroeconomics 29, 541-554.

Durlauf, S. N. \& D. T. Quah (1999) The new empirics of economic growth, Ch. 4 in J.B. Taylor and M. Woodford (eds.), Handbook of Macroeconomics, Vol. IA, North-Holland, Amsterdam, 231-304.

Fernandez, C., E. Ley, \& M. F. J. Steel (2001a) Model uncertainty in cross-country growth regressions. Journal of Applied Econometrics 16, 563-576.

Fernandez, C., E. Ley, \& M. F. J. Steel (2001b) Benchmark priors for Bayesian model averaging. Journal of Econometrics 100, 381-427.

Fischer, S. (1993) The role of macroeconomic factors in growth. Journal of Monetary Economics $32(3), 485-512$.

George, E. I. \& R. E. McCulloch (1997) Approaches for Bayesian variable selection. Statistica Sinica 7, 339-373.

Grier, K. B. \& G. Tullock (1989) An empirical analysis of cross national economic growth. Journal of Monetary Economics 24(2), 259-276.

Gylfason, T. \& T. Herbertsson (2001) Does inflation matter for growth? Japan and the World Economy 13, 405-428.

Hall, R. \& C. I. Jones (1999) Why do some countries produce so much more output per worker than others? Quarterly Journal of Economics 114(1), 83-116.

Judson, R. A. \& A. L. Owen (1999) Estimating dynamic panel data models: A guide for macroeconomist. Economic Letters 65, 9-15.

Khan, M. S. \& A. S. Senhadji (2001) Threshold effects in the relationship between inflation and growth. IMF Staff Papers 48(1), 1-21.

Koop, G., R. León-González, \& R. Strachan (2012) Bayesian model averaging in the instrumental variable regression model. Journal of Econometrics 171, 237-250.

Koop, G. \& L. Tole (2004a) Measuring the health effects of air pollution: To what extent can we really say that people are dying from bad air? Journal of Environmental Economics and Management 47, 30-54.

Koop, G. \& L. Tole (2004b) An investigation of thresholds in air pollution-mortality effects. Working Paper No.04/20.

Kormendi, R. \& P. Meguire (1985) Macroeconomic determinants of growth: Cross-country evidence. Journal of Monetary Economics 16, 141-163. 
Kremer, S., A. Bick, \& D. Nautz (2009) Inflation and growth: New evidence from a dynamic panel threshold analysis. SFP 649 discussion paper No 36. Zuberlin: Humboldt-Universitat.

León-González, R. \& D. Montolio (2012) Endogeneity and panel data in growth regression: A Bayesian model averaging approach. GRIPS discussion paper.

Moral-Benito, E. (2010) Panel growth regressions with general pre-determined variables: Likelihood-based estimation and Bayesian averaging. CEMFI Working Papers - 1006

Moral-Benito, E. (2012) Determinants of economic growth: A Bayesian panel data approach. Review of Economics and Statistics 94, 566-579.

Romer, P. M. (1990) Endogenous technological change. Journal of Political Economy 98, 71102.

Roodman, D. (2009) How to do xtabond2: An introduction to difference and system GMM in Stata. Stata Journal 9, 86-136.

Sala-i-Martin, X. X. (1997a) I just ran four million regressions. Mimeo, Columbia University.

Sala-i-Martin, X. X. (1997b) I just ran two million regressions. American Economic Review 87, 178-183.

Sala-i-Martin, X., G. Doppelhofer, \& R. Miller (2004) Determinants of long-term growth: A Bayesian averaging of classical estimates (BACE) approach. American Economic Review 94, 813-835.

Solow, R. (1956) A contribution to the theory of economic growth. Quarterly Journal of Economics 70(1), 65-94.

Temple, J. (1999) The new growth evidence. Journal of Economic Literature 37, 112-156.

Vinayagathasan, T. (2013), Inflation and economic growth: A dynamic panel threshold analysis for Asian economies. Journal of Asian Economics 26, 31-41.

William R. Hauk, Jr. \& R. Wacziarg (2004) A Monte Carlo study of growth regression. NBER technical working paper, 0296

Windmeijer, F. (2005) A finite sample correction for the variance of linear efficient two-step GMM estimator. Journal of Econometrics 126, 25-51.

Wooldridge Jeffrey M. (2010) Econometric analysis of cross-section and panel data (ch 10), 2nd ed. MIT Press: Cambridge, London.

Yilmazkuday, H. (2011) Thresholds in the finance-growth nexus: A cross country analysis. The World Bank Economic Review 25(2), 278-295. 
Table 1: Data Description and Source(s)

\begin{tabular}{lll}
\hline Variables & Description and Source & Source $(s)$ \\
\hline y & GDP per capita growth rate in purchasing power parity (PPP) 2005 & PWT 7.0 \\
log_initial & GDstant prices & \\
inv & Annual percentage change of GDP per capita dedicated to investment & PWT 7.0 \\
& in PPP 2005 constant prices & PWT 7.0 \\
inf $^{6}$ & Average percentage change of CPI for the year & EW \\
gpop & Annual growth rate of population & WDI \\
open & Share of export plus import in percentage of GDP in 2005 constant prices & PWT 7.0 \\
tot & Export value divided by import value (2000 = 100) & WDI \\
lfpr & Percentage of total population between ages 15 and 65 & WDI \\
gce & Government consumption share of GDP per capita converted in PPP & PWT 7.0 \\
& 2005 constant prices & \\
prim & Gross enrollment rate in primary education (\% of total enrollment & WDI \\
& regardless of age) & \\
secnd & Gross enrollment rate in secondary education (\% of total enrollment & WDI \\
pi & regardless of age) & \\
pop & Price level of investment in PPP 2005 constant prices & PWT 7.0 \\
popdn & Total population in million & WDI \\
\hline
\end{tabular}

Note: PWT represents Penn World Table, EW denotes Economy Watch, and WDI indicates World Development Indicator.

\footnotetext{
${ }^{6}$ In order to allow for threshold effects, we enter inflation into the model in the form of two regressors, (i) inflation below the threshold level and (ii) inflation above the threshold level (see Section 3 for the details).

${ }^{7}$ Since the school enrollment rate data for certain periods for some of the Asian countries are not available in the World Development Indicator data base, we collected the data of primary school enrollment ratio for Bangladesh for 1996-2004 from http://www.igs-bracu.ac.bd/UserFiles/File/archive_file/Working\%20paper.pdf and for 2005-2009 from http://www.indexmundi.com/facts/bangladesh/school-enrollment. The primary school enrollment ratio of Vietnam for 2002-2009 was collected from http://www.indexmundi.com/facts/vietnam/school-enrollment. We collected the secondary school enrolment ratio of Bhutan for the periods of 1981, 1988, and 1994 from the Asian Economic Outlook. The primary school enrollment ratio of Saudi Arabia for the periods 1980, 1985, 1990, 1991, 1995, and 2004 was collected from http://www.tradingeconomics.com/saudi-arabia/school-enrollment-primarypercent-gross-wb-data.html, and the secondary school enrollment ratio for the periods of 1980, 1985, 1990, 1991,

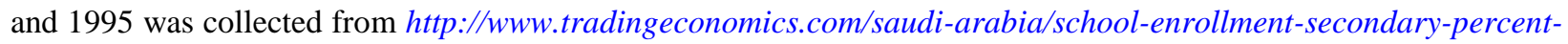
gross-wb-data.html.
} 
Table 2: Summary Statistics of Full Sample

\begin{tabular}{lccccc}
\hline \multicolumn{1}{c}{ Variable } & Observation & Mean & Std. Dev. & Min & Max \\
\hline y & 345 & 2.837 & 4.944 & -22.28 & 20.56 \\
log_initial & 345 & 3.737 & 0.575 & 2.805 & 5.176 \\
log_infl & 345 & 0.498 & 1.067 & -7.439 & 2.046 \\
infl & 345 & 8.148 & 12.33 & -6.439 & 111.2 \\
inv & 345 & 28.05 & 11.16 & 5.605 & 67.92 \\
gpop & 345 & 2.616 & 2.271 & -5.966 & 18.06 \\
open & 345 & 90.87 & 55.84 & 7.776 & 386.6 \\
tot & 345 & 82.65 & 23.72 & 25.76 & 192.9 \\
lfpr & 345 & 64.42 & 9.918 & 42.50 & 84.05 \\
gce & 345 & 10.14 & 5.397 & 2.747 & 39.24 \\
prim & 345 & 99.05 & 16.87 & 34.43 & 151.3 \\
secnd & 345 & 59.46 & 24.95 & 4.512 & 99.77 \\
pi & 345 & 51.89 & 28.75 & 10.69 & 259.6 \\
pop & 345 & $1.21 \mathrm{e}+8$ & $2.97 \mathrm{e}+8$ & 159278.5 & $1.33 \mathrm{e}+9$ \\
popdn & 345 & 733.1 & 2575.29 & 3.928 & 18743.9 \\
\hline
\end{tabular}

Source: Author's calculations based on data from Penn World Table (PWT 7.0), Economy Watch, and World Development Indicator. All the statistics are in two-year arithmetic averages over the period 1980-2009. 
Table 3: List of Countries and Summary Statistics for Inflation and Growth Rate

\begin{tabular}{|c|c|c|c|c|c|c|}
\hline \multirow[b]{2}{*}{ Region } & \multirow[b]{2}{*}{ Country } & \multirow[b]{2}{*}{$i d$} & \multirow[b]{2}{*}{$T_{i}$} & \multicolumn{3}{|c|}{ Mean } \\
\hline & & & & Inflation & $\begin{array}{l}\text { Log of } \\
\text { inflation }\end{array}$ & $\begin{array}{l}\text { Growth rate of } \\
\text { GDP per capita }\end{array}$ \\
\hline \multirow{7}{*}{ South Asia } & Bangladesh & 2 & 13 & 8.096 & 0.862 & 2.392 \\
\hline & Bhutan & 3 & 11 & 7.319 & 0.811 & 5.039 \\
\hline & India & 7 & 15 & 8.078 & 0.881 & 4.083 \\
\hline & Maldives & 15 & 9 & 4.978 & 0.155 & 6.172 \\
\hline & Nepal & 16 & 12 & 9.095 & 0.912 & 1.757 \\
\hline & Pakistan & 18 & 8 & 8.735 & 0.892 & 2.769 \\
\hline & Sri Lanka & 23 & 10 & 11.986 & 1.055 & 3.487 \\
\hline \multirow{3}{*}{ East Asia } & China & 4 & 15 & 5.697 & 0.358 & 8.614 \\
\hline & Hong Kong & 6 & 11 & 3.855 & -0.226 & 4.211 \\
\hline & Macao & 13 & 8 & 17.077 & 0.463 & 6.646 \\
\hline \multirow{7}{*}{$\begin{array}{c}\text { South East } \\
\text { Asia }\end{array}$} & Indonesia & 8 & 15 & 9.472 & 0.498 & 3.433 \\
\hline & Laos & 12 & 15 & 33.110 & 0.740 & 4.538 \\
\hline & Malaysia & 14 & 15 & 3.178 & 0.416 & 3.615 \\
\hline & Papua New Guinea & 19 & 11 & 7.987 & 0.869 & -0.032 \\
\hline & Philippines & 20 & 15 & 9.684 & 0.877 & 1.129 \\
\hline & Thailand & 25 & 15 & 3.899 & 0.310 & 4.172 \\
\hline & Vietnam & 27 & 8 & 13.984 & 0.648 & 5.820 \\
\hline \multirow{10}{*}{$\begin{array}{c}\text { Western } \\
\text { Asia }\end{array}$} & Bahrain & 1 & 15 & 1.661 & -0.459 & -0.469 \\
\hline & Cyprus & 5 & 15 & 4.065 & 0.546 & 2.750 \\
\hline & Iran & 9 & 12 & 18.764 & 1.239 & 2.314 \\
\hline & Jordan & 10 & 15 & 5.262 & 0.526 & 0.697 \\
\hline & Kuwait & 11 & 15 & 3.528 & 0.341 & 0.048 \\
\hline & Oman & 17 & 15 & 2.023 & -0.634 & 2.126 \\
\hline & Qatar & 21 & 15 & 4.211 & 0.514 & 3.155 \\
\hline & Saudi Arabia & 22 & 7 & 2.660 & -0.130 & 1.020 \\
\hline & Syria & 24 & 15 & 12.010 & 0.587 & 1.308 \\
\hline & United Arab Emirates & 26 & 15 & 4.747 & 0.628 & -0.658 \\
\hline
\end{tabular}

Source: Author's calculations based on data from the sources of Penn World Table (PWT 7.0) for growth rate of GDP per capita and Economy Watch for inflation rate over the period 1980-2009. $T_{i}$ is the number of observations per country. 
Table 4: BMA Estimation for Coefficients of Exogenous Variables

\begin{tabular}{lcrccc}
\hline Variable & Probability & $2.50 \%$ & $97.50 \%$ & Mean & Positive \\
\hline inv & 0.995 & 0.0228 & 0.1853 & 0.1091 & 0.988 \\
inf_low & 0.006 & 0.0000 & 0.0000 & 0.0001 & 0.003 \\
inf_high & 0.536 & -2.5416 & 0.0000 & -0.8280 & 0.003 \\
gpop & 0.005 & 0.0000 & 0.0000 & -0.0004 & 0.001 \\
open & 0.996 & -0.0231 & 0.0262 & 0.0039 & 0.654 \\
tot & 0.311 & -0.0456 & 0.0000 & -0.0077 & 0.014 \\
lfpr & 0.281 & 0.0000 & 0.4973 & 0.0971 & 0.281 \\
gce & 0.851 & -0.6262 & 0.0000 & -0.3514 & 0.000 \\
prim & 0.051 & -0.0318 & 0.0000 & -0.0016 & 0.008 \\
secnd & 1.000 & -0.0878 & 0.0538 & -0.0019 & 0.522 \\
pi & 0.012 & 0.0000 & 0.0000 & -0.0002 & 0.001 \\
pop & 1.000 & $-1.8 \mathrm{e}-8$ & $2.1 \mathrm{e}-8$ & $4.6 \mathrm{e}-9$ & 0.738 \\
popdn & 0.069 & $-6.9 \mathrm{e}-6$ & 0.0006 & $1.9 \mathrm{e}-5$ & 0.043 \\
\hline
\end{tabular}

Note: The column Probability gives the posterior probability that the coefficient is different from zero. The following two columns give the lower and upper bounds of a 95\% credible interval. The column Mean gives the posterior mean of the coefficient. The column Positive gives the posterior probability that the coefficient is positive.

\section{Table 5: BMA Estimation for Coefficient of Endogenous Regressor}

\begin{tabular}{ccrrrc}
\hline Variable & Probability & $2.50 \%$ & $97.50 \%$ & Mean & Negative \\
\hline Initial & 0.172 & -12.369 & 32.045 & 8.7462 & 0.036 \\
\hline
\end{tabular}

Note: The column Probability gives the posterior probability that the coefficient is different from zero. The following two columns give the lower and upper bounds of a 95\% credible interval. The column Mean gives the posterior mean of the coefficient. The column Negative gives the posterior probability that the coefficient is negative. 
Table 6: BMA Estimation Results of Equation (4), Treating All Explanatory Variables as Exogenous and with No Fixed Effects.

\begin{tabular}{lccc}
\hline \multicolumn{1}{c}{ Variable } & Probability & Mean & SD \\
\hline log_initial & 34.30 & -0.5528 & 0.8270 \\
inv & 100.0 & 0.1056 & 0.0244 \\
inf_low & 0.000 & 0.0000 & 0.0000 \\
inf_high & 1.100 & -0.0066 & 0.0819 \\
gpop & 11.60 & -0.0276 & 0.0741 \\
open & 0.000 & 0.0000 & 0.0000 \\
tot & 60.60 & -0.0173 & 0.0165 \\
lfpr & 67.20 & 0.0468 & 0.0394 \\
gce & 0.000 & 0.0000 & 0.0000 \\
prim & 6.800 & -0.0018 & 0.0081 \\
secnd & 67.70 & -0.0269 & 0.0212 \\
pi & 0.000 & 0.0000 & 0.0000 \\
pop & 95.70 & $2.28 \mathrm{e}-9$ & $1.1 \mathrm{e}-9$ \\
popdn & 93.20 & $2.81 \mathrm{e}-4$ & $1.21 \mathrm{e}-4$ \\
\hline
\end{tabular}

Note: Column 1 indicates the posterior inclusion probability of a variable entering the model as an exogenous regressor, column 2 denotes the posterior mean of the coefficient, and column 3 represents the standard deviation of parameters. The number of observations is 345 .

Table 7: One-Step System GMM, FE, and LSDVC Estimation Results of Equation (4)

\begin{tabular}{|c|c|c|c|c|c|c|}
\hline Variables & \multicolumn{2}{|c|}{ System GMM } & \multicolumn{2}{|c|}{$F E$} & \multicolumn{2}{|c|}{$L S D V C$} \\
\hline log_initial & -9.995 & $(-1.44)$ & -2.480 & $(-0.83)$ & $-7.877 *$ & $(-1.77)$ \\
\hline inv & $0.116^{*}$ & $(1.78)$ & $0.148 * * *$ & $(4.05)$ & $0.122 * *$ & $(2.51)$ \\
\hline Inf_low & -0.223 & $(-0.70)$ & 0.034 & $(0.90)$ & -0.029 & $(-0.09)$ \\
\hline Inf_high & $-1.474 *$ & $(-1.75)$ & $-1.440 * *$ & $(-2.42)$ & $-2.257 * * *$ & $(-2.89)$ \\
\hline gpop & 0.047 & $(0.13)$ & -0.063 & $(-0.42)$ & 0.095 & $(0.53)$ \\
\hline open & $0.062 * *$ & $(2.61)$ & 0.010 & (1.01) & 0.017 & $(0.94)$ \\
\hline tot & -0.029 & $(-1.17)$ & $-0.024 *$ & $(-1.71)$ & -0.008 & $(-0.44)$ \\
\hline lfpr & $0.522 * *$ & $(2.51)$ & $0.327 * * *$ & (2.89) & $0.301 *$ & (1.87) \\
\hline gce & $-0.360 * *$ & $(-2.35)$ & $-0.404 * * *$ & $(-3.50)$ & -0.258 & $(-1.47)$ \\
\hline prim & -0.071 & $(-1.09)$ & -0.015 & $(-0.52)$ & -0.040 & $(-0.89)$ \\
\hline secnd & 0.002 & $(0.05)$ & 0.001 & $(0.04)$ & 0.051 & (1.28) \\
\hline pi & -0.001 & $(-0.90)$ & -0.009 & $(-0.77)$ & -0.004 & $(-0.32)$ \\
\hline pop & $2.4 \mathrm{e}-8 * *$ & $(2.15)$ & $1.1 \mathrm{e}-8$ & (1.48) & $1.21 \mathrm{e}-8$ & $(1.25)$ \\
\hline popdn & 0.001 & $(0.90)$ & -0.0002 & $(-0.32)$ & -0.001 & $(-0.23)$ \\
\hline y.L1 & & & & & $0.244 * * *$ & $(3.72)$ \\
\hline Observation & \multicolumn{2}{|c|}{299} & \multicolumn{2}{|c|}{345} & \multicolumn{2}{|c|}{265} \\
\hline
\end{tabular}

Note: t-statistics are given within parenthesis; *** indicates $p<0.01, * * p<0.05$, and $* p<0.1$. 